\title{
Contributing Factors of Neonatal Death from Mother with Preeclampsia in Indonesia
}

\author{
Ernawati $^{1}$, Kristanti Wanito Wigati ${ }^{1}$, Austana Nur Hafizh ${ }^{2}$, Budi Santoso ${ }^{1}$, Nursalam ${ }^{3}$ \\ ${ }^{1}$ Faculty of Medicine, ${ }^{2}$ Student in Faculty of Medicine, ${ }^{3}$ Faculty of Nursing, Universitas Airlangga
}

\begin{abstract}
Background: Preeclampsia is one of the main causes of maternal and neonatal morbidity and mortality in developing countries. The infant mortality rate in Indonesia has decreased but is still quite high. The purpose of this study was to analyze the factors that contribute to the death of infants from mothers with preeclampsia. Method: This research is a design retrospective cross-sectional study conducted in women with a history of preeclampsia are recorded in the data Dr. Soetomo hospital over a period of one year. Total respondents were 324 . Demographic data on preeclamptic mothers (gestational age, age, parity and mode of delivery) and infant mortality data were collected which were then analyzed descriptively and chi-square test. Results: The results showed a significant relationship between maternal age with preeclampsia $(\mathrm{p}=$ $0.005)$, age of maternal pregnancy with preeclampsia $(p=0.000)$ and mode of delivery of mothers with preeclampsia ( $p=0.000)$ with the incidence of death in infants, and none a significant relationship between maternal parity status with preeclampsia $(p=0.043)$ with the incidence of death in infants. Conclusion: factors that contribute to infant mortality from mothers with preeclampsia are age, gestational age, and mode of delivery.
\end{abstract}

Keywords: contributing factors; preeclampsia; neonatal death

\section{INTRODUCTION}

Sustainable Development Goals (SDGs) Program in Indonesia one of which is to reduce the neonatal mortality rate and child mortality rate. Events of infant or child death in Indonesia. The number of infant mortality cases dropped from 33,278 in 2015 to 32,007 in 2016, and in 2017 there were 10,294 cases. Similarly, the maternal mortality rate dropped from 4,999 in 2015 to 4912 in 2016 and in 2017 there were 1712 cases $^{1}$. Despite the decline, the figure is still high.

Data from the World Health Organization, maternal mortality in the world amounted to 289,000 in 2013 , maternal deaths occurred every day about 800 women died due to complications of pregnancy and childbirth. The main trial of maternal deaths in Indonesia are bleeding, preeclampsia and infection. Preeclampsia is a hypertensive condition $\mathrm{k}$ late pregnancy characterized by increased blood pressure and proteinuria ${ }^{2}$. In developing countries, preeclampsia is one of the main causes of maternal mortality ranging from $1.5-2.5$ percent and infants range from 45-50 percent ${ }^{3}$. Based on these data, the percentage of infant deaths due to preeclampsia is greater than that of mothers. Infant mortality occurs due to several risk factors for preeclamptic mothers, such as preeclampsia in previous pregnancies, symptoms of chronic hypertension, pregnancies of more than 40 years, and others that have been carried out in advance ${ }^{4}$.

The impact of preeclampsia other than on the mother also affects the baby. The condition of preeclampsia can interfere with blood flow to the placenta and fetus which can cause low birth weight babies, prematurity, asphyxia, respiratory distress syndrome, apnea ${ }^{5}$ and infant mortality ${ }^{6}$. Babies who survive after birth from mothers with pre-eclampsia are also at risk of developing disorders due to disturbances while still a fetus.

Some factors that cause the handling of preeclampsia in pregnant women are lacking are lack of knowledge, lack of self-awareness and poor antenatal care ${ }^{7}$. Preeclampsia conditions will increase the risk of mother and baby experiencing cardiovascular complications ${ }^{8}$, maternal age $>30$ years, parity, history of hypertension, and no antenatal care ${ }^{9,10}$. 
Research on preeclampsia that has been done more often looks at the risk factors of the mother and the effects on the fetus. But the contributing factors, especially in Indonesia, have not been found. The purpose of this study was to analyze the factors that contribute to infant mortality in women with preeclampsia.

\section{METHOD}

This research is a retrospective study conducted in the public hospital area of Dr. Soetomo Surabaya. The sample of this study is medical record data of preeclampsia patients in the period of January to December 2017 as many as 324 were taken by consecutive sampling.. Patient data is collected sequentially based on medical record numbers to avoid repetition of data and confusion when filling in data. Pre-eclampsia diagnosis is established by obstetricians. Pre-eclampsia diagnosis is blood pressure $>140 / 90 \mathrm{mmHg}$ with proteinuri $>+2$. The independent variables of this study were age, gestational age, parity and mode of delivery. The dependent variable in this study was infant mortality defined as death in the first 28 days of life. Data were analyzed descriptively and chi-square test.

\section{RESULTS}

Table of factors that contribute to infant mortality in women with pre-eclampsia

\begin{tabular}{|c|c|c|c|c|c|c|}
\hline \multirow{2}{*}{ Variable (mother) } & \multicolumn{3}{|c|}{ Infant } & \multirow[b]{2}{*}{$\%$} & \multirow[b]{2}{*}{$\begin{array}{l}\text { Total } \\
\text { N (\%) }\end{array}$} & \multirow[t]{2}{*}{$\mathbf{P}$} \\
\hline & Life & $\%$ & Mortality & & & \\
\hline Age (years) & & & & & & 0.005 \\
\hline$<20$ & 14 & 4,3 & 0 & 0,0 & $14(4)$ & \\
\hline $20-35$ & 180 & 55,6 & 31 & 9,6 & $211(65)$ & \\
\hline$>35$ & 72 & 22,2 & 27 & 8,3 & $99(31)$ & \\
\hline Age of mother's pregnancy (weeks) & & & & & & 0.000 \\
\hline$<28$ & 9 & 2,8 & 21 & 6,5 & $30(9.3)$ & \\
\hline $28-34$ & 91 & 28,1 & 30 & 9,2 & $121(37.3)$ & \\
\hline$>34$ & 166 & 51,2 & 7 & 2,2 & $173(53.4)$ & \\
\hline Paritas & & & & & & 0.463 \\
\hline Nulipara & 96 & 29,6 & 20 & 6,2 & $116(35.8)$ & \\
\hline Primipara & 81 & 25,0 & 14 & 4,3 & $95(29.3)$ & \\
\hline Multipara & 89 & 27,5 & 24 & 7,4 & $113(34.9)$ & \\
\hline How to deliver & & & & & & 0.000 \\
\hline Spontaneous vaginal discharge & 47 & 14,5 & 13 & 4,0 & $60(18.5)$ & \\
\hline Vaginal induction & 16 & 4,9 & 12 & 3,7 & $28(8.6)$ & \\
\hline Vagina with instruments & 9 & 2,8 & 4 & 1,2 & $13(4)$ & \\
\hline Perabdominam & 193 & 59,6 & 26 & 8,0 & $219(67.7)$ & \\
\hline No data & 1 & 0,3 & 3 & 1,0 & $4(1.2)$ & \\
\hline
\end{tabular}

Most respondents are aged 20-35 years (65\%). Most of the respondents' gestational age was $>34$ weeks (53.4\%). Most of the respondents were nullipara (35.8\%) and most of them had abdominal labor (67.7\%). 
Most respondents with pre-eclampsia with a baby who died were aged 20-35 years as many as 31 events (9.6\%). Infant mortality from preeclampsia mothers was 30 events (9.2\%) from pre-eclampsia mothers with 28-34 weeks gestational age. Infant mortality in preeclampsia mothers was 20 events $(6.2 \%)$ occurred in preeclampsia mothers with nulliparous parity, and infant mortality occurred as many as 26 events $(8 \%)$ occurred in pre-eclampsia mothers by means of gestational birth.

Statistical test results showed a significant relationship between maternal age with preeclampsia with the incidence of infant mortality ( $p=0.005)$, and there was no significant relationship between the parity status of mothers with pre-eclampsia and mortality in infants $(p=0.463)$. The results of statistical tests also showed a significant relationship between the age of maternal pregnancy with preeclampsia $(\mathrm{p}=0.000)$ and the method of delivery of mothers with preeclampsia $(0.000)$ with the incidence of infant mortality.

\section{DISCUSSION}

The age of mothers with preeclampsia has a significant relationship with the incidence of infant mortality. Infant mortality occurs in preeclamptic mothers in the age group of 20-35 years and age $>35$ years.

The results of this study are in line with other studies which state that maternal age with young pre-eclampsia is associated with the risk of infant mortality ${ }^{11,12}$. Maternal age at risk of developing pre-eclampsia occurs in the age group $<20$ years and $>35$ years.

In this study, besides that most of the respondents in this study were preeclamptic mothers aged 20-35 years. In preeclamptic mothers aged 20-35 years are included in the productive age where they are emotionally mature, especially in the face of pregnancy. In addition, the reproductive organs have also been mature and balanced ${ }^{13}$. Several other factors such as early treatment of the condition of preeclampsia and maternal conditions when treatment can affect maternal conditions.

Pregnancy age of mothers with preeclampsia has a significant relationship with the incidence of infant mortality. The infant mortality from mothers with preeclampsia most common in gestational age 28-34 weeks and $<28$ weeks.
The results of this study are in line with previous studies showing that the gestational age of mothers with preeclampsia is related to the morbidity and mortality of infants who born ${ }^{14}$. Other studies have shown that the high risk of infant mortality in preeclamptic mothers in the preterm period (gestational age less than 37 weeks) ${ }^{15,16}$ and will be more severe at a gestational age of fewer than 24 weeks ${ }^{17}$.

Babies born in the preterm period have a high risk of experiencing low birth weight babies, respiratory disorders such as asphyxia ${ }^{18}$ that occur due to pulmonary growth disorders ${ }^{6}$, intrauterine growth restriction (IUGR) and hematological disorders. Epidemiological research states that babies born to mothers with preeclampsia have a high risk of developing diabetes and cardiovascular disorders. The condition of preeclampsia can aggravate the baby's condition which is probably caused by impaired placental function due to preeclampsia or maternal system response to placental inability.

The method of delivery of mothers with preeclampsia has a significant relationship with the incidence of infant mortality. The majority of preeclamptic mothers in this study gave birth to a method of palpation. As well as the incidence of infant mortality from preeclamptic mothers occurred in the group of preeclamptic mothers who gave birth to a method of domination.

Previous studies have suggested that abdominal methods of childbirth will increase the risk of respiratory distress in infants that can cause infant death ${ }^{19,20}$. In addition, the method of childbirth with abdominal can increase the risk of respiratory disorders in infants compared with childbirth with vaginal delivery. Previous studies have shown that abdominal delivery ${ }^{21}$ cannot improve maternal and perinatal outcomes or reduce mortality and morbidity ${ }^{22}$.

Most mothers with preeclampsia do the method of labor by abdominal. The reason for the majority of methods of delivery per abdominal is because abdominal labor is the definitive treatment in patients with severe pre-eclampsia. The risk of childbirth in women who experience severe pre-eclampsia is very high because it can threaten the life of the mother and baby, so it is necessary to end the pregnancy by giving birth per abdominal. The condition of preeclampsia which has a negative impact on the baby as well as ways of abdominal delivery which increase the risk of disorders 
in infants can increase the risk of infant mortality from mothers with preeclampsia.

The parity status of mothers with preeclampsia does not have a significant relationship with the incidence of infant mortality. The total parity status of preeclamptic mothers in the study was almost the same in the nullipara, primiparous and multiparous groups.

Previous studies have shown that the status of nulliparous parity will increase the risk of the occurrence of preeclampsia ${ }^{23}$ that would increase the risk of death in infants. Nulliparous pregnancies experience angiogenic imbalances so they are prone to pre-eclampsia compared to multiparous pregnancies ${ }^{24}$. The results of this study indicate that the incidence of infant mortality from mothers with pre-eclampsia occurs in nulliparous parity status although there is no statistically significant relationship.

This study has several limitations because it is done retrospectively such as some data relating to maternal preeclampsia conditions such as income, increased maternal weight during pregnancy, or other diseases that can worsen the condition of preeclampsia.

The results of this study have implications for policies related to health interventions and treatment of women with preeclampsia, maternal complications, and complications in infants. This study has limitations, the severity of preeclampsia is still not differentiated and several other factors such as antenatal care visits, knowledge, and accompanying complications have not been measured. So it needs further study of these factors related to the incidence of infant mortality from mothers with preeclampsia.

\section{CONCLUSION}

Preeclampsia can threaten the mother and baby and can increase morbidity and mortality in infants. Factors that contribute to infant mortality from mothers with preeclampsia are maternal age, maternal gestational age, and maternal delivery method. The need for early antenatal care needs to be conveyed to pregnant women in order to screen crews for risk of preeclampsia and prevent worsening of the disease.

\section{RECOMMENDATION}

Preeclampsia is a preventable medical condition. Early pregnancy screening early and appropriate antenatal care can reduce the risk of morbidity and mortality in infants of mothers who experience pre-eclampsia. Increasing public awareness and health workers on the prevention of pre-eclampsia needs to be done through health education or including pre-eclampsia screening at standard examinations in pregnant women.

Ethical Clearance: This research has received ethical approval from the ethics committee of the general hospital health research area of Dr. Soetomo Surabaya number 0171 / KEPK / IV / 2018.

\section{Conflict of Interest: None}

Funding: Self-funding.

\section{REFERENCES}

1. Ministry of Health Republic of Indonesia. Inilah Capaian Kinerja KEMENKES RI Tahun 2015- 2017 [Internet]. Ministry of Health Republic of Indonesia. 2017 [cited 2018 Sep 12]. Available from: http://www.depkes.go.id/article/ print/17081700004/-inilah-capaian-kinerjakemenkes-ri-tahun-2015--2017.html

2. Davey D, MacGillivray I. The classification and definition of the hypertensive disorders of pregnancy. Am J Obs Gynecol. 1988;158:892-8.

3. Shamsi U, Saleem S, Nishtee N. Epidemiology and risk factors of preeclampsia; an overview of observational studies. Al Ameen J Med Sci [Internet]. 2013;6(4):292-300. Available from: https://pdfs.semanticscholar. org/ 06 a c / 70 c 07 e 5309 e 2 c 7 c b 20819 ff2a214579df2e1.pdf

4. The American College of Obstetricans and Gynecologists. Preeclampsia and Hypertension in Pregnancy: Resource Overview [Internet]. Womens Health care Physician. 2013 [cited 2018 Aug 7]. Available from: https://www.acog.org/ Womens-Health/Preeclampsia-and-Hypertensionin-Pregnancy

5. Mendola P, Mumford, Sunni L Männistö TI, Holston A, Reddy UM, Laughon SK. Controlled Direct Effects of Preeclampsia on Neonatal Health After Accounting for Mediation by Preterm Birth. J Pharmacogenetic. 2015;26(1):17-26.

6. Backes $\mathrm{CH}$, Markham K, Moorehead P, Cordero L, Nankervis CA, Giannone PJ. Maternal 
Preeclampsia and Neonatal Outcomes. J Pregnancy. 2011;

7. Singhal S, Deepika A, Nanda S. Maternal and perinatal outcome in severe pre-eclampsia and eclampsia. J South Asian Fed Obstet Gynecol. 2009;1(3):25-8.

8. O'Tierney-Ginn P, Lash G. Beyond pregnancy: modulation of trophoblast invasion and its consequences for fetal growth and longterm children's health. J Reprod Immunol. 2014;104(105):37-42.

9. Bilano VL, Ota E, Ganchimeg T, Mori R, Souza JP. Risk Factors of Pre-Eclampsia/Eclampsia and Its Adverse Outcomes in Low- and MiddleIncome Countries: A WHO Secondary Analysis. PLoS One. 2014;9(3).

10. Andriani F. Faktor Faktor yang berhubungan dengan Preeklampsia di RSU Dr Soetomo Surabaya tahun 2009 [Internet]. Universitas Airlangga; 2010. Available from: http://lib.unair. ac.id

11. Neal S, Channon AA, Chintsanya J. The impact of young maternal age at birth on neonatal mortality: Evidence from 45 low and middle income countries. Ploss one. 2018;

12. Tavassoli F, Ghasemi M, Ghomian N, Ghorbani A, Tavassoli S. Maternal and perinatal outcome in nulliparious women complicated with pregnancy hypertension. J Pak Med Assoc. 2010;60(9):70710.

13. Cahyani SL, Sulansi, Batbual B. Age, Parity, Antenatal Care, and Pregnancy Complication as Contributing Factors of Low Birth Infants. Int J Sci Basic Applies Res. 2016;30(3):1-7.

14. Bombrys A, Barton J, Habli M, Sibai B. Expectant management of severe preeclampsia at $27(0 / 7)$ to 33(6/7) weeks' gestation: maternal and perinatal outcomes according to gestational age by weeks at onset of expectant management. Am J Perinatol. 2009;26:441-6.

15. Harmon QE, Huang L, Umbach DM, Klungsøyr K, Engel SM, Magnus P, et al. Risk of Fetal Death With Preeclampsia. Obs Gynecol.
2015;125(3):628-635.

16. Swamy, MK, Patil K, Nageshu S. Maternal and perinatal outcome during expectant management of severe pre-eclampsia between 24 and 34 weeks of gestation. J Obs Gynaecol India. 2012;62:4138.

17. Oostwaard $M$ van, Eerden $L$ van, Laat $M$ de, Duvekot J, Erwich J, Bloemenkamp K, et al. Maternal and neonatal outcomes in women with severe early onset pre-eclampsia before 26 weeks of gestation, a case series. Int joiurnal Obstet Gynaecol. 2017;124(9).

18. Jail L. Respiratory morbidity in late-preterm infants: prevention is better than cure! Am J Perinatol. 2008;25(2):75-8.

19. Tita AT, Landon MB, Spong C., Shriver EK. Maternal-Fetal Medicine Units Network. Timing of elective repeat cesarean delivery at term and neonatal outcomes. N Engl J Med. 2009;360:111120.

20. Saadat M, Nejad SM, Habibi G, Sheikhvatan M. Maternal and Neonatal Outcomes inWomen with Preeclampsia. Taiwan J Obs Gynecol. 2007;46(3).

21. Witlin A, Saade G, Mattar F, Sibai B. Predictors of neonatal outcome in women with severe preeclampsia or eclampsia between 24 and 33 weeks' gestation. Am J Obs Gynecol. 2000;182:607-11.

22. Coppage K, Polzin W. Severe preeclampsia and delivery outcomes: Is immediate cesarean delivery beneficial? Am J Obs Gynecol. 2002;186:921-3.

23. Moldenhauer J, Stanek J, Warshak C, Khoury J, Sibai B. The frequency and severity of placental findings in women with preeclampsia are gestational age dependent. Am J Obs Gynecol. 2003;189(4):173-7.

24. Bdolah Y, Uriel Elchalal, Shira NatansonYaron, Hadas Yechiam, Tali Bdolah-Abram CG, Goldman-Wohl D, Milwidsky A, Rana S, Karumanchi SA, et al. Relationship between nulliparity and preeclampsia may be explained by altered circulating soluble fms-like tyrosine kinase 1. J Hypertens Pregnancy. 2014;33(2). 